\title{
Interlocutory Marital Status
}

National Cancer Institute

\section{Source}

National Cancer Institute. Interlocutory Marital Status. NCI Thesaurus. Code C76241.

The condition existing when an order or judg ement is considered temporary until either a specified period of time has passed or specific information is provided to assist in rendering a permanent decision. 